Tracking and maintenance of goal-relevant location information in narratives

\author{
William H. Levine \& Jessica E. Kim
}

University of Arkansas

Author Note

William H. Levine and Jessica E. Kim, Department of Psychological Science, University of Arkansas.

This research was supported by a University of Arkansas Honors College Undergraduate Research Grant to JEK. This research was reported as part of JEK's honors thesis conducted at the University of Arkansas under the direction of WHL. Portions of these data were reported at the $27^{\text {th }}$ Annual Meeting for the Society of Text \& Discourse in Philadelphia, PA in 2017.

We thank JEK's committee members, Jim Lampinen and Lisa Margulis, for their helpful comments on the presentation of this research. Cami Conroy, Emily Educate, Buddy Flores, Angel Houts, Brian Jekel, Kolby Knight, John McNeil, Jessie Merriman, Bailey Parsons, Joe Quinn, Woodrow Ramey, Victoria Radke, and Lauren Taylor assisted with data collection and/or helped generate the stimuli used in this research. Ed O’Brien, Emily Smith, Joe Magliano, and three anonymous reviewers provided critical feedback on an earlier version of this manuscript.

The full set of materials used in this research is publicly available, along with raw data, a preregistered data-analysis plan, and analysis code, at https://doi.org/10.17605/OSF.IO/A98W5

Correspondence concerning this manuscript should be addressed to William H. Levine, 216 Memorial Hall, Department of Psychological Science, University of Arkansas, Fayetteville, AR 72701. Email: whlevine@uark.edu 


\begin{abstract}
Two experiments were conducted to examine whether readers maintain location in a highlyaccessible state in memory during narrative comprehension, while reading narratives with goals closely tied to locations that story protagonists needed to reach. College undergraduates $(n=185$, $n=100$ ) read short, experiment-generated narratives manipulated in three ways. First, protagonist location was manipulated such that the goal was completed or not, making subsequent critical sentences consistent or inconsistent, respectively, with the last-described location. Second, text distance between the manipulation of location and the later target sentence was varied, such that the critical sentences were close to or distant from the last mention of location. Third, location words that explicitly mentioned the protagonist's location were either present or not in the critical sentences. Readers took longer to read critical sentences when the protagonist had not been described as reaching the goal location, suggesting that readers were maintaining location information in highly-accessible state. This effect emerged with or without explicit location words in the critical sentences and with near or distant backgrounding. These results are discussed in the context of scenario-based and memory-based theories of comprehension.
\end{abstract}

Keywords: discourse processing; language comprehension; situation models 


\section{Tracking and maintenance of goal-relevant location information in narratives}

The man in black fled across the desert, and the gunslinger followed.

- Stephen King (The Dark Tower: The Gunslinger, 1982, p. 11)

In many fictional narratives, the location and movement of protagonists is closely tied to their goals. In Stephen King's (1982) fantasy novel, The Dark Tower: The Gunslinger, the protagonist, Roland, pursues his antagonist, the man in black, from a small town to a farm; across a desert and into mountains; and finally through tunnels within a mountain. All of his movements are driven by his pursuit of the man in black, or the sub-goals generated in service of this larger goal. That character goals are generators of action in narrative - including movements - has long been an underpinning of theories of understanding stories and human action more generally (e.g., Schank \& Abelson, 1977). Given this, and given the evidence that understanding and keeping track of character goals plays a critical role in understanding stories (e.g., Suh \& Trabasso, 1993), it seems intuitive that the cognitive processes involved in the comprehension of narratives would involve keeping track of the location and movement of the characters in a story. Despite this intuition, the research literature on the storage, maintenance, and retrieval of information about a protagonist's location and the location of narrative action has produced mixed results about these processes. We believe that this is in part due to studying movement and location changes without attempting to link these clearly to character goals. We designed the research reported here to try to understand the representation of location information over stretches of text, especially after the location information ceases to be the current focus of the text. Critically, given our intuition about the link between location, movement, and character goals, the narratives we used in our research closely linked location information to character goals, thereby arguably making location critical to understanding the ongoing action. 


\section{Situational and location processing $\&$ representation}

Some theoretical accounts of the processing and mental representation of narratives (e.g., Kurby \& Zacks, 2012; Zwaan \& Radvansky, 1998) have focused on how situational dimensions like time, location, characters, and character goals are incorporated into that representation, which is often called a situation model (van Dijk \& Kintsch, 1983). A variety of evidence supports two general claims about the tracking of these dimensions, sometimes called eventindexing (Zwaan, Langston, \& Graesser, 1995), in narrative comprehension. The first claim is that changes in dimensions lead to additional processing to update or revise the situation model (Gernsbacher, 1990; Zwaan \& Radvansky, 1998). Changes in dimensions (e.g., a time shift of more than a moment) are generally positively related to reading time (e.g., Rinck \& Weber, 2003; Weingartner \& Myers, 2013; Zwaan, 1996; Zwaan, Magliano, \& Graesser, 1995; Zwaan, Radvansky, Hilliard, \& Curiel, 1998), thought to reflect the additional resources devoted to updating a situation model. Moreover, brain activity increases in synchrony with situational dimension changes (Speer, Zacks, \& Reynolds, 2007). The second claim is that changes in the dimensions in the situation described by a text are reflected in the structure of the mental representation of the text, such that information associated with a no-longer-current dimension (e.g., a prior temporal period) is less available in memory than information associated with a current dimension. Generally, memory for information that was presented prior to a change in a dimension is worse than memory for the same information without an intervening change in dimension. This finding has emerged in explicit memory tasks such as recognition of words from earlier in a text (e.g., Levine \& Klin, 2001; Weingartner \& Myers, 2013; Zwaan, 1996) and in implicit memory tasks, as indexed by increased reading time or ERPs indicating difficulty with integrating information on text that requires access to information in memory from a prior 
situation, like reference comprehension (e.g., Anderson, Garrod, \& Sanford, 1983; Ditman, Holcomb, \& Kuperberg, 2008; Kelter, Kaup, \& Claus, 2004; Thompson \& Radvansky, 2015). Despite the general support for event-indexing, evidence pertinent to specific role of location changes in these processes is mixed, especially with respect to the fate of the representation of location information after it is no longer the focus of a text. Some findings in the literature are consistent with the hypothesis that readers encode location of narrative characters when first encountered and when the characters change location, and further that this information is maintained in active memory in a readily accessible ${ }^{1}$ manner (e.g., Levine $\&$ Klin, 2001). For example, Levine and Klin had subjects read short narratives like the one excerpted in (1) below:

(1) Maria and Bill went for a day hike in a state forest ... After a several hour hike, they sat down to eat lunch. [It was terrible how out of shape they were, and they were still both in their 20s. Bill swore he would get back to playing hockey and Maria said she'd start running.] They both felt exhausted. The trees provided nice shade.

Readers experienced no apparent additional difficulty processing associated anaphors (e.g., the trees in the final sentence) when the bracketed intervening text appeared between the location setting information (e.g., in the state forest) and the anaphor, relative to when the bracketed text was not present. By contrast, in a version of the example in which the protagonists were no longer in the forest, readers experienced difficulty processing the trees. Further, information about a protagonist's current location has been found to be more readily accessible in memory than a former location in explicit-memory tasks that require readers to respond to location probewords (Levine \& Klin, 2001; Radvansky \& Copeland, 2010; Rapp \& Taylor, 2004).

\footnotetext{
${ }^{1} \mathrm{By}$ accessible we mean that the information is activated enough so that it influences moment-by-moment processing (cf. Cook, Guérard, Was, \& O'Brien, 2007).
} 
Despite the findings described above, there is substantial empirical evidence inconsistent with the claims that spatial location is carefully tracked and that it is represented in memory in an active, readily-accessible manner. For example, unlike situational dimensions such as time and character goals, changes in location information have frequently been shown to not be associated with an increase in processing, indexed by reading time (e.g., Radvansky \& Copeland, 2010; Rapp \& Taylor, 2004; Rinck \& Weber, 2003; Zacks, Speer, \& Reynolds, 2009; Zwaan et al., 1998). Moreover, some findings using location probe-word tasks (de Vega, 1995), and others using an inconsistency-detection paradigm (Smith \& O'Brien, 2012), have shown that evidence of readily-accessible current location information may be due to text cues reactivating location information from long-term memory. Without these cues, readily-accessible location information seems to occur only if readers memorize or are instructed to strategically track location information (e.g., Hakala, 1999; Morrow, Greenspan, \& Bower, 1987; Smith \& O'Brien, 2012).

The claim that the level of activation of location information is governed in large part by explicit text cues is consistent with the memory-based text-processing framework, articulated primarily by Myers and O'Brien (1998; O'Brien \& Myers, 1998) and McKoon, Gerrig, and colleagues (Gerrig \& McKoon, 1998; Gerrig \& O'Brien, 2005; McKoon \& Ratcliff, 1992). This framework posits that the limited capacity of working memory leads to a need for readers to activate information from long-term memory - from earlier text and/or from general knowledge - for comprehension to proceed smoothly. Critically, activation of information from long-term memory is not typically accomplished by strategic search but is instead a product of passive activation of information from long-term memory, a feature of many models of retrieval from long-term memory (e.g., Gillund \& Shiffrin, 1984; Hintzman, 1999; Ratcliff, 1978). Thus, the cues that are available in a text are critical for understanding what information will be activated 
and accessible on a moment-by-moment basis. With respect to the representation of location information, this claim was explicitly tested by Smith and O'Brien (2012), who found that readers showed no evidence of detecting location-based inconsistencies in passages like the one excerpted in (2) below:

(2) Lisa just completed a long workout at her favorite gym... When she was done she was tired and needed to get home for dinner. Lisa walked past the marble steps inside the health club. She went through the door and left the building. Lisa sat on the marble steps [outside] to wait a bit.

Readers did not slow down when the protagonist was performing an action (e.g., being outside and sitting on marble steps) in a location that was inconsistent with the information in the story (e.g., the marble steps are on the inside of the building), unless there was an explicit locationrelated memory cue (e.g., the bracketed word outside) in the passage or if they were specifically instructed to keep track of location information. Smith and O'Brien performed several studies in which they manipulated the amount of spatial information available in text cues, finding that the more information present in the cue, the more evidence there was that readers maintained spatiallocation information in an active state in memory. They concluded that their results were consistent with a cue-based mechanism for encoding and tracking location information, such that readers keep track of and update spatial information upon encountering text cues related to previously-mentioned location information..

These strong claims about the updating and maintenance of location information are based on studies that used stimuli that may not represent typical narratives very well. The example (see excerpt 2 above) from Smith and O'Brien (2012) has a protagonist with a goal of going home for dinner, but the protagonist's location on the marble steps is not relevant to the 
goal. Some other materials from this study ${ }^{2}$ share this quality of providing information about the protagonist's location that is incidental to the protagonist's goal (e.g., a character is described as being either on the first or second floor of an airport to check their bags). Similarly, de Vega's (1995) materials are more descriptive than narrative, as illustrated in (3) below, with the result being that the manipulation of the protagonist's location (illustrated in parentheses) may tell little about typical narrative comprehension processes:

(3) Maria was visiting an Italian town for the first time. In one of the squares there is a bronze sculpture of a soldier riding a horse. On one side of the square there is an old palace. Inside the palace is a luxurious marble staircase. Maria went into (out from) the palace and walked a few steps. She looked around with admiration ${ }^{3}$.

Certainly there are changes in location in narrative that are incidental to or even independent of character goals - especially in film in the case of continuity edits (cf. Magliano \& Zacks, 2011) but if the experimental materials used do not represent typical narratives, there are limitations on the generality of the conclusions vis-à-vis narrative comprehension (cf. Graesser, Millis, \& Zwaan, 1997; Kreuz \& Roberts, 1993).

\section{Experiment 1}

In this research, we tested the hypothesis that the updating and maintenance of location information about protagonists is a cue-based process, using a location-inconsistency-detection paradigm like that used by Smith and O'Brien (2012; see also O'Brien \& Albrecht, 1992).

Critically, we used narrative stimuli in which a protagonist's location was closely tied to the main goal the protagonist sought to achieve. The importance of the relevance or salience of location information to the ongoing narrative action is one that has been raised and even tested a number

\footnotetext{
2 Thanks to Emily Smith and Ed O'Brien for sharing their materials.

${ }^{3}$ This is a translation of the original Spanish materials, provided in de Vega's (1995) appendix.
} 
of times (Levine \& Klin, 2001; Radvansky \& Copeland, 2000; Sundermeier, van den Broek, \& Zwaan, 2005). Radvansky and Copeland found that sentences describing location information were read more quickly and that they were remembered better in off-line (i.e., after reading) memory tasks when they were relevant to the narrative action than when they were not. Sundermeier et al. found that spatial information - about objects and the location of objects rather than about protagonist location - became more accessible in memory when it became causally relevant to ongoing narrative action. The importance of the overlap between location and causal information was underscored by Zwaan, Magliano, and Graesser (1995), who had subjects reading literary texts and found that location changes were associated with increases in reading time only when they co-occurred with causal discontinuities (see also Rinck \& Weber, 2003).

We wrote passages that were designed to be representative of pleasure-reading material, with narratives that contained a character, an urgent goal, and an obstacle possibly preventing them from reaching that goal. The passages appeared in one of eight versions based on three manipulated variables. First, our passages (see Table 1 for an example and the online supplement Table 1: Example passage from the present research
Introduction: A hurricane was rolling in from the Gulf Coast, and Tom needed to evacuate.
Traffic was so bad that he arrived at the airport late for his flight, and now he had only thirty
minutes to make it from the parking lot to his seat on the plane. The airport was absolutely
packed.
Goal/location manipulation
(consistent) Tom managed to get through security with enough time to take his seat on his plane.
(inconsistent) The lines to get past security were so long that Tom was stuck waiting in line.
Backgrounding manipulation (additional distant backgrounding in brackets): The wind was
increasing and the sky was already black. [The incoming storm was supposed to be the worst of
the season. Tom never thought much about climate change, but everyone on the news and on
Facebook was talking about it constantly. The hurricane was stronger than initially forecast, and
there had been little time to prepare. Tom's phone had been ringing nonstop with calls from
worried relatives watching the news.]
Critical sentences (explicit cue in brackets): Tom [sat in his seat on the plane and] heard the
announcement for everyone to fasten their seatbelts. Tom could hear someone near him praying
out loud.
Conclusion: Everyone around Tom was nervous at the sound of rain beginning to fall outside.

for a full set) contained location information that was either consistent or inconsistent with the critical sentences of the 
passage that appeared later. If consistent, this sentence's location information indicated that the character's goal had been completed. If inconsistent, the sentence's location information was incompatible with the goal having been completed. Second, the text backgrounding distance between the location information and consistent or inconsistent critical sentence was varied to make the location information either close or distant from the target sentence, with the longer distance expected to remove location information from working memory (e.g., Albrecht \& Myers, 1995). Third, there were two critical sentences, a target and a spillover. The target sentence contained either a cue that made the character's current location explicit, or no such cue, so that the location was only implicitly alluded to, providing a test of whether such cues are necessary to reinstate location information. The spillover sentence made no explicit reference to location and was included to detect possible carryover effects from the target sentence. The use of spillover sentences in the inconsistency methodology has been standard since at least the research of Albrecht and O'Brien (1993) and has been used by many different research teams (e.g., Chan, Foy, \& Magliano, 2018; Sparks \& Rapp, 2011; Therriault \& Raney, 2007). The rationale for the use of a spillover sentence is often left implicit, at best. Among others, Mitchell (1984) argued that spillover effects may be due to uncompleted processes that arise on one segment that are not resolved until a later segment. O'Brien and Cook (2016) argue explicitly that even quickly activated information may not be integrated or validated until after a delay. In our task, given the relative complexity of the materials, which involved integration of material both locally and globally, it is plausible that some processing involved in integrating the information in the target sentence may not be completed by the time the reader begins reading the spillover sentence.

There were several related predictions made for this experiment. Inconsistent location 
information was expected to cause a slowdown in the critical sentences while readers had to search their memory or update their situation models, as compared to consistent location information; thus, reading time should be longer in the inconsistent condition than in the consistent condition. This inconsistency effect was expected to be more pronounced in the near condition, when the information is still in working memory, than in the distant condition after several lines of text have backgrounded the information; this might manifest itself in a larger inconsistency effect in the near than in the far condition and possibly one that is shifted more to the spillover sentence than the target sentence. In the same way, explicit cue words in the critical sentence were expected to make readers more likely to retrieve location information that causes inconsistent locations to be more noticed; again, this may manifest as a larger inconsistency effect when the cue is present than when it absent and possibly shifted more to the spillover sentence than the target sentence. However, we believed that the link between goal and location information would allow readers to be able to efficiently retrieve location information and notice if the critical sentence is inconsistent with the earlier location, even in the absence of specific cues and even when several sentences have removed that information from working memory.

\section{Method}

\section{Subjects}

For this study, 198 subjects $^{4}$ from introductory psychology courses at the University of Arkansas voluntarily participated in exchange for course credit toward partial fulfillment of a research requirement. All were native-English speakers.

\section{Materials}

Twenty-four experimental passages were written for use in this study, along with 27

\footnotetext{
${ }^{4}$ Details of sample size determination are provided in the pre-registration for this research.
} 
fillers. Some of the experimental passages were adapted from passages from those of Smith and O'Brien (2012), but most were new. Each experimental passage followed the template illustrated by the sample passage in Table 1. Each passage began with 53 or 54 words introducing a character and an urgent goal the character needed to achieve in a short period of time, in a location different from where the character was initially described to be. Most of the goals were the sort a college student could relate to (e.g., being late to class and missing an exam), but some were not (e.g., needing to escape from zombies). This section of the passage contained the setup for the manipulation of the character's location, and thereby also the status of the goal the character was trying to achieve, by clearly describing the current location, goal, and the location associated with that goal. In the consistent-location condition, the character was described in a new location consistent with completing the goal; in the inconsistent-location condition, the character would either not move or would move to some other location than where the character needed to go to complete the goal. For each passage, the consistent and inconsistent locationmanipulation sentences were equated for the number of words $(M=14.3, S D=1.7)$ and explicitly named a location to avoid confusion in passages revealed by norming to be confusing ${ }^{5}$. This was followed by backgrounding conditions intended to manipulate whether the location information would remain in working memory or not. This consisted of either 10 (close condition) or 71 (distant condition) words of backgrounding information not related to the goal or location; the close backgrounding was identical to the first 10 words of the distant backgrounding section. Subsequent to the backgrounding, critical sentences, with or without

\footnotetext{
${ }^{5}$ One group of subjects $(n=19)$ read long-backgrounding versions of the stories, half with a consistent location and half with an inconsistent location section (see Table 1), with critical sentences removed. They answered from memory three open-ended questions after each story, including one question about where the protagonist was at the end of the story. Any story that did not generate $>80 \%$ agreement with respect to location was revised and went through a second norming $(n=39)$. All stories had $>80 \%$ agreement about location after the second norming.
} 
location cues, described a situation that was inconsistent or consistent with the last-described location of the character; these varied in length between (but not within) cue conditions, so we controlled for line length in the analyses reported below. For example (see Table 1), Tom was still waiting in line in the inconsistent condition, but now he was either implied (no cue condition) or explicitly stated (cue condition) to be on his plane. The cue words were meant to make the current location directly known to the reader, so in Tom's case included the specific words in his seat on the plane. A spillover sentence followed to capture any delayed effects of consistency or other factors, and then the passage was wrapped up with a sentence or two of conclusion.

Filler passages were similar in structure and length to experimental passages but varied in length and content to obscure the systematic nature of the experimental manipulations and therefore to obscure the purpose of the experiment from subjects.

A single yes-no comprehension question followed each passage to test whether subjects were paying attention.

\section{Design}

Cue presence in the target sentences was manipulated between subjects, with each subject seeing only passages either with explicit-location cues or with no cues. Location and backgrounding distance were manipulated within subjects, so subjects saw all possible combinations of those two variables, but never saw multiple versions of the same story. All of these variables were manipulated within passages, so that each passage had eight distinct versions.

For each cue condition, four lists of stimuli were created with the following constraints: In each list, one-quarter of the experimental passages appeared in each of the four location-by- 
backgrounding combinations. Across lists, each passage was seen by one-quarter of the subjects in each of the four location-by-backgrounding combinations.

\section{Procedure}

Subjects were recruited using Sona Systems, online software for scheduling research participation; the description of the experiment indicated that subjects would read short stories and answer questions about them. Subjects were tested individually on a computer using DirectRT software (Jarvis, 2008) and were randomly assigned to either the explicit-location or no-cue condition and to a stimulus list. After being presented with instructions, subjects read three practice filler stories to get accustomed to using the left and right arrow keys (marked Y and $\mathrm{N}$ on their keyboards, respectively) to answer the yes-no comprehension questions that followed each story. Stories were presented one line at a time, and subjects advanced through the stories by pressing the spacebar. They were not allowed to go back and reread, and they were not given feedback about the answers they gave to the comprehension questions.

Experimental passages were presented in random order along with filler passages presented in a fixed order; experimental and filler passages alternated, so that subjects did not read two experimental passages in a row. The random order of experimental passages was different for each subject. The same three practice filler passages were presented to all subjects before the alternating experimental and filler passages began, to ensure subject facility with the procedure.

Subjects read all passages and answered a comprehension question following each. Reading times were recorded for each line. After subjects finished reading the passages, they were given a questionnaire that probed for their understanding of the purpose of the experiment. Afterward, they were debriefed, given credit, and thanked. For the data analyzed below, the 
experiment took a mean of about 32 minutes to complete $(S D=6.8)$.

\section{Results}

\section{Data Screening \& Exclusion}

Of 198 subjects, the data from 12 were excluded from further analyses due to low accuracy on comprehension questions (i.e., $<75 \%$ correct), and the data from one other subject were lost due to a file-naming error. For the remaining 185 subjects, mean accuracy on comprehension questions was $90.7 \%(S D=5.7 \%)$.

Outlying reading times (i.e., individual observations, not entire subjects) were defined as being more than 2.5 standard deviations from the mean of all reading times. This excluded $1.8 \%$ of the data from further analysis.

\section{Modeling \& Analytic Details}

We employed linear mixed models to analyze the reading times, using the $\mathrm{R}$ ( $\mathrm{R}$ Core Team, 2017) package lme4 (Bates, Maechler, Bolker, \& Walker, 2015) using maximum likelihood estimation. Separate models were fit for the target line and the spillover line. Location status (consistent or inconsistent), cue type (explicit or none), and backgrounding length (close or distant), including all possible interactions, were analyzed as fixed-effects factors, along with line length in letters. We first fit models with maximal random-effects structure that included random intercepts for both subjects and stories, as well as random slopes for each of the repeated-measures fixed factors (Barr, Levy, Scheepers, \& Tily, 2013). Maximal models did not converge. Thus, we started with a random-slopes-only random-effects structure and added in random slopes for main effects and then interactions incrementally, keeping only those random slopes that led to a converging model, lowered AIC for the model, and increased model fit significantly. Where $p$-values are reported, they are based on error $d f$ estimated using 
Satterthwaithe's approximation (cf. Luke, 2017), implemented by the lmerTest package

(Kuznetsova, Brockhoff, \& Christiansen, 2015). An alpha level of .05 was adopted as the criterion for significance, except for planned follow-up analyses, where Bonferroni-adjusted alpha levels were used.

Conventional by-subjects and by-items analysis of variance results are presented in the Appendix. These match the results produced by using linear mixed models.

\section{Target Line Results}

Model-estimated means and $95 \%$ confidence intervals ${ }^{6}$ for target lines appear in the top half of Table 2 .

\begin{tabular}{|c|c|c|c|c|c|}
\hline \multirow{4}{*}{$\begin{array}{l}\text { line } \\
\text { target }\end{array}$} & \multirow{4}{*}{$\begin{array}{l}\text { location } \\
\text { consistent }\end{array}$} & \multicolumn{4}{|c|}{ backgrounding } \\
\hline & & \multicolumn{2}{|c|}{ close } & \multicolumn{2}{|c|}{ distant } \\
\hline & & cue & no cue & cue & no cue \\
\hline & & $2145[1974,2317]$ & $2429[2272,2586]$ & $2173[2019,2326]$ & $2407[2251,2562]$ \\
\hline \multirow{3}{*}{ spillover } & inconsistent & $2362[2191,2532]$ & $2497[2341,2652]$ & $2308[2155,2462]$ & $2459[2304,2615]$ \\
\hline & consistent & $2074[1933,2216]$ & $2154[2009,2299]$ & $2052[1910,2193]$ & $2094[1949,2239]$ \\
\hline & inconsistent & $2173[2031,2315]$ & $2301[2156,2446]$ & 2046 [1904, 2188] & $2239[2094,2384]$ \\
\hline
\end{tabular}

For exposition, a consistency effect is reading time in the inconsistent condition minus reading time in the consistent condition, such that positive values indicate that the inconsistency led to longer reading times. There was a significant consistency effect on the target line: estimated reading times on this line, controlling for line length in letters, were longer when it was inconsistent with the protagonist's location $(2404 \mathrm{~ms}, S E=57)$ than when it was consistent (2284 ms, $S E=57), F(1,3980.8)=32.29, p<.001$. The effect of cue presence, after controlling for line length, was significant, with estimated reading times longer when there was no location-cue

\footnotetext{
${ }^{6}$ Note that the cell CIs are not as informative as the consistency-effect CIs, which appear in Figure 1. This is true of the estimated means in Table 3, with Experiment 2's results, as well, with the consistency-effect CIs displayed in Figure 2 .
} 
present ( $2448 \mathrm{~ms}, S E=77)$ than when there was a location-cue present (2247 ms, $S E=77), F(1$, $176.4)=3.96, p=.048$. There was no significant main effect of backgrounding $(F<1)$.

The main effect of location is qualified by a significant location-by-cue interaction (see Figure 1$), F(1,3998.7)=7.79, p=.005$. The consistency effect on the target line was larger when there was a location-cue present. To explore this interaction, two planned simple-effects tests of the consistency effect, one with and one without a location-cue present, were executed using a Bonferroni-adjusted alpha level of .025 for each. When a location-cue was present, there was a significant consistency effect of $176 \mathrm{~ms}(S E=29), t(3988.0)=6.10, p<.001$. When there was no location-cue present, the consistency effect was $60 \mathrm{~ms}(S E=29.9)$ and was not significant, $t(3822.0)=2.01, p=.045$.

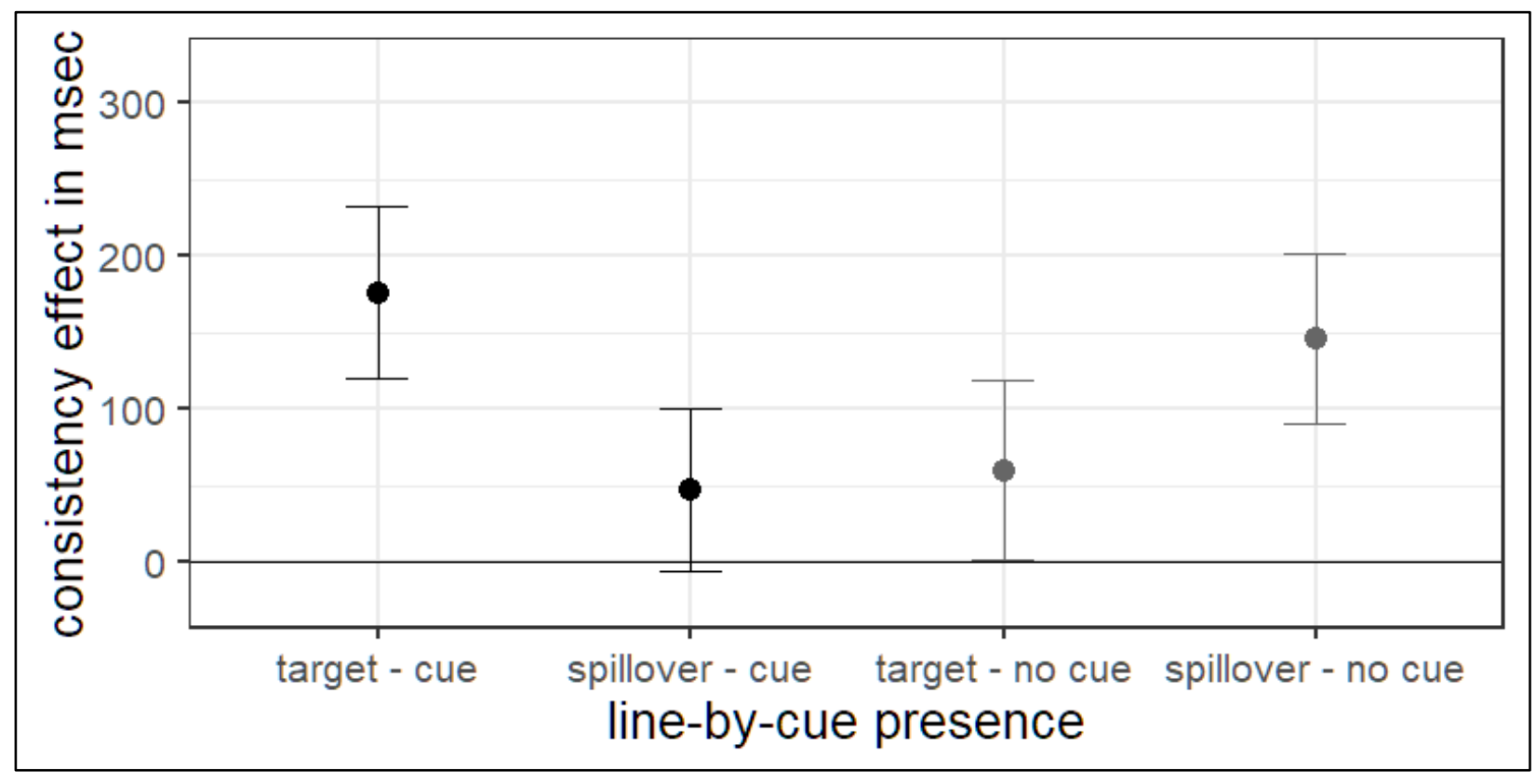

Neither the location-by-backgrounding, cue-by-backgrounding, nor the three-way interaction was significant (all $F \mathrm{~s}<1.4$ ). Because the cue-by-backgrounding interaction is of theoretical interest (cf. Albrecht \& Myers, 1995; Smith \& O'Brien, 2012), planned simple-effects tests of the consistency effect were executed, one in the distant backgrounding condition and one 
in the close backgrounding condition, with a Bonferroni-adjusted alpha level of .025 for each. The consistency effect was significant in both the distant backgrounding condition $(94 \mathrm{~ms}, S E=$ $29), t(3982.0)=3.21, p=.001$, and in the close backgrounding condition (142 ms, $S E=29)$, $t(3984.0)=4.83, p<.001$.

\section{Spillover Line Results}

Model-estimated means and 95\% confidence intervals for spillover lines appear in the bottom half of Table 2 .

There was a significant consistency effect on the spillover line: estimated reading times on this line, controlling for line length in letters, were longer when it was inconsistent with the protagonist's location $(2187 \mathrm{~ms}, S E=59)$ than when it was consistent (2092 ms, $S E=59), F(1$, $4204.3)=24.15, p<.001$. The effect of cue presence, after controlling for line length, was not significant, although estimated reading times were notably longer when there was no locationcue present $(2197 \mathrm{~ms}, S E=70)$ than when there was location-cue present (2086 ms, $S E=68)$, $F(1,184.3)=2.24, p=.136$. Unlike on the target line, there was a significant effect of backgrounding on the spillover line, with estimated reading times being longer in the close condition $(2173 \mathrm{~ms}, \mathrm{SE}=59)$ than in the distant condition $(2105 \mathrm{~ms}, S E=59), F(1,4205.2)=$ $11.99, p<.001$

The main effect of location is qualified by a significant location-by-cue interaction (see the Figure $), F(1,4196.9)=6.42, p=.011$. The consistency effect on the spillover line was larger when there was no location-cue present. Two planned simple-effects tests of the consistency effect, one with and one without a location-cue present, were executed using a Bonferroniadjusted alpha level of .025 for each. When a location-cue was present, the consistency effect of $47 \mathrm{~ms}(S E=27)$ was not significant, $t(4362.0)=1.72, p=.085$. When there was no location-cue 
present, the consistency effect of $146 \mathrm{~ms}(S E=28)$ was significant, $t(4038.0)=5.17, p<.001$.

Neither the location-by-backgrounding, cue-by-backgrounding, nor the three-way interaction was significant (all $F \mathrm{~s}<1.9$ ). Because of the theoretical importance of the cue-bybackgrounding interaction, planned simple-effects tests of the consistency effect were executed, one in the distant backgrounding condition and one in the close backgrounding condition, with a Bonferroni-adjusted alpha level of .025 for each. The consistency effect was significant in both the distant backgrounding condition $(70 \mathrm{~ms}, S E=28), t(4189.0)=2.53, p=.011$, and in the close backgrounding condition $(122 \mathrm{~ms}, S E=28), t(4366.0)=4.42, p<.001$.

\section{Experiment 2}

Experiment 2 was a replication of Experiment 1, using a completely within-subjects design, conducted to examine the reliability of the pattern of results in Experiment 1 and to provide further data to inform conclusions.

\section{Method}

\section{Subjects}

For this study, 103 native-English-speaking subjects from introductory psychology courses at the University of Arkansas voluntarily participated in exchange for course credit toward partial fulfillment of a research requirement. Because the cue-presence variable was not manipulated between subjects, the target sample size was one-half that of Experiment 1.

\section{Materials \& Procedure}

The materials and procedure from Experiment 1 were used in this experiment.

\section{Design}

Unlike in Experiment 1, cue presence in the target sentences was manipulated within subjects, so each subject saw passages with both explicit-location cues and with no cues. As in 
Experiment 1, location and backgrounding distance were manipulated within subjects. Thus, each subject saw all possible combinations of all three variables. No subject saw multiple versions of the same story. All of these variables were manipulated within passages, so that each passage had eight distinct versions.

Eight lists of stimuli were created with the following constraints: In each list, one-eighth of the experimental passages appeared in each of the possible combinations of variable levels. Across lists, each passage was seen by one-eighth of the subjects in each of the possible combinations of the levels of the independent variables.

\section{Results}

\section{Data Screening \& Exclusion}

Of 103 subjects, data from three subjects were excluded from further analyses due to low accuracy on comprehension questions (i.e., < 75\% correct). For the remaining 100 subjects, mean accuracy on comprehension questions was $91.5 \%(S D=5.4 \%)$. Outlying reading times were defined as in Experiment 1, resulting in the exclusion of $2.0 \%$ of the data from further analysis.

\section{Modeling \& Analytic Details}

Modeling was executed as in Experiment 1.

\section{Target Line Results}

Model-estimated means and 95\% confidence intervals for target lines appear in the top half of Table 3 .

There was a significant consistency effect on the target line: estimated reading times on this line, controlling for line length in letters, were longer when it was inconsistent with the protagonist's location $(2370 \mathrm{~ms}, S E=25)$ than when it was consistent (2162 ms, $S E=25), F(1$, 
$2070.9)=49.34, p<.001$. The effect of cue presence was not significant, $F<1$. There was a significant effect of backgrounding, with estimated reading times being longer in the close condition (2312 ms, $S E=25)$ than in the distant condition (2219 ms, $S E=25), F(1,2070.7)=$ $9.95, p=.002)$.

\begin{tabular}{|c|c|c|c|c|c|}
\hline \multirow{4}{*}{$\begin{array}{l}\text { line } \\
\text { target }\end{array}$} & \multirow{4}{*}{$\begin{array}{l}\text { location } \\
\text { consistent }\end{array}$} & \multicolumn{4}{|c|}{ backgrounding } \\
\hline & & \multicolumn{2}{|c|}{ close } & \multicolumn{2}{|c|}{ distant } \\
\hline & & cue & no cue & cue & no cue \\
\hline & & $2171[2015,2326]$ & $2228[2071,2384]$ & $2180[2025,2336]$ & $2067[1911,2223]$ \\
\hline \multirow{3}{*}{ spillover } & inconsistent & $2452[2299,2605]$ & $2398[2243,2554]$ & $2355[2200,2510]$ & $2273[2116,2430]$ \\
\hline & consistent & $2020[1872,2167]$ & $2015[1868,2163]$ & $2015[1867,2163]$ & $1897[1750,2045]$ \\
\hline & inconsistent & 2178 [2030, 2326] & $2101[1953,2249]$ & 2054 [1907, 2202] & $2003[1855,2151]$ \\
\hline
\end{tabular}

Unlike in Experiment 1, the main effect of location was not qualified by a significant location-by-cue interaction (see Figure 2), $F<1$. The consistency effect was of a similar

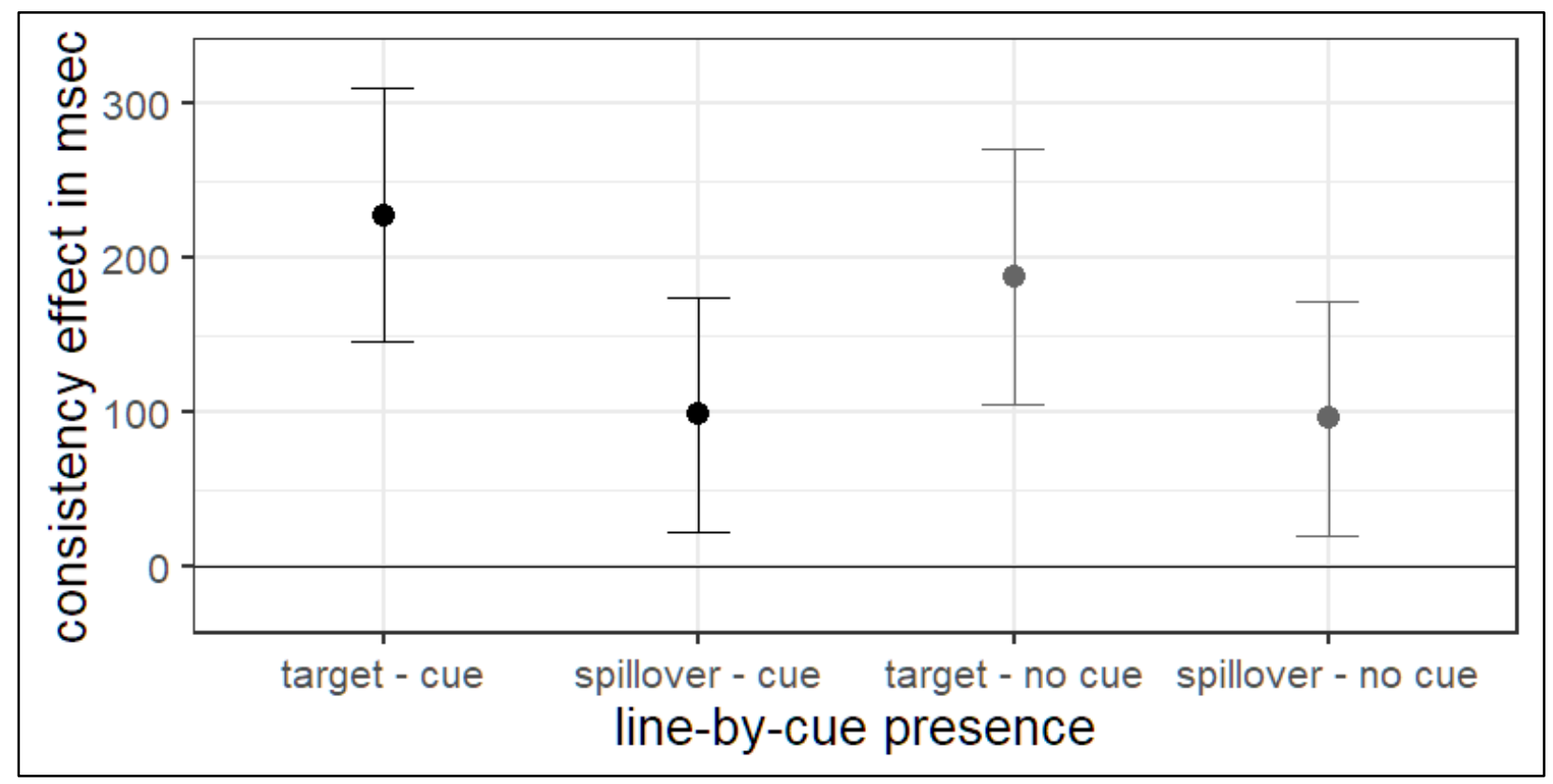

magnitude on the target line with and without a cue present. To facilitate comparison with the results of Experiment 1, two planned simple-effects tests of the consistency effect, one with and one without a location-cue present, were executed using a Bonferroni-adjusted alpha level of 
.025 for each. When a location-cue was present, there was a significant consistency effect of 228 ms $(S E=41.8), t(2075.8)=5.46, p<.001$. When there was no location-cue present, the consistency effect was $188 \mathrm{~ms}(S E=42.2)$ and was significant, $t(2074.0)=4.46, p<.001$.

Neither the location-by-backgrounding, cue-by-backgrounding, nor the three-way interaction was significant (all $F \mathrm{~s}<2.9$ ). Because the cue-by-backgrounding interaction is of theoretical interest, planned simple-effects tests of the consistency effect were executed, one in the distant backgrounding condition and one in the close backgrounding condition, with a Bonferroni-adjusted alpha level of .025 for each. The consistency effect was significant in both the distant backgrounding condition $(190 \mathrm{~ms}, S E=41.9), t(2070.8)=4.53, p<.001$, and in the close backgrounding condition $(226 \mathrm{~ms}, S E=41.9), t(2071.0)=5.40, p<.001$.

\section{Spillover Line Results}

Model-estimated means and 95\% confidence intervals for spillover lines appear in the bottom half of Table 3 .

There was a significant consistency effect on the spillover line: estimated reading times on this line, controlling for line length in letters, were longer when it was inconsistent with the protagonist's location $(2084 \mathrm{~ms}, S E=67)$ than when it was consistent $(1987 \mathrm{~ms}, S E=67), F(1$, 2123.3) $=12.63, p<.001$. The effect of cue presence, after controlling for line length, was significant, with estimated reading times being longer when there was a location-cue present (2067 ms, $S E=67)$ than when there was no location-cue present (2004 ms, $S E=67), F(1$, 2121.2) $=5.23, p=.022$. There was a significant effect of backgrounding on the spillover line, with estimated reading times being longer in the close condition $(2078 \mathrm{~ms}, S E=67)$ than in the distant condition $(1992 \mathrm{~ms}, S E=67), F(1,2123.3)=9.79, p=.002$. None of the interactions were significant on the spillover line (all $F \mathrm{~s}<1.61$ ). 


\section{General Discussion}

The main purpose of this research was to examine whether readers maintain location in a highly-accessible state in memory during narrative comprehension, in the context of stories with important narrative goals that were closely tied to locations the story protagonists needed to reach. Critically, we also tested whether explicit location reminder cues are needed for location information to be maintained that highly-accessible state. We presented passages that were manipulated in three ways to college undergraduate subjects, a sample that arguably represents a population of skilled adult readers reading in their native language. First, the location of the protagonist was manipulated such that their goal was completed or not, making a subsequent target sentence consistent or inconsistent, respectively, with the protagonist's last-described location. Second, the text distance between the manipulation of location and the later target sentence was manipulated, such that the critical information was either close to or distant from the location's encoding and when it needed to be retrieved. Third, location words that either explicitly mentioned the protagonist's location were included or not in the target sentence. If readers noticed in the target sentence when the protagonist had not been described as reaching the goal location, their reading times should slow down if they notice the inconsistency and try to make sense of it. Our results show that this was the case.

Most critically, cue presence and backgrounding were significant moderators of the consistency effect in Experiment 1, but not in Experiment 2. In Experiment 1, the pattern of the goal and cue interaction differed between the target sentence and the subsequent spillover sentence. On the target line, cue words increased the magnitude of the consistency effect, but on the spillover line this effect was reduced in magnitude. By contrast, in the cue-absent condition, the consistency effect appeared weakly in the target line but became more pronounced on the 
spillover line. In Experiment 2, the inconsistency effect was about as robust in the cue-present as in the cue-absent condition on both the target and spillover sentences. This suggests that cues may of course be useful to help readers bring location information to a highly-active state, but given the pattern of data and the narrower confidence intervals in Experiment 2, they may not be necessary. This is inconsistent with the claim that location information would not be activated without a location cue upon reaching an inconsistency (Smith \& O'Brien, 2012), or more generally that cues are needed to retrieve location information (de Vega, 1995), as significant consistency effects remained with or without the cues, even as early as possible (i.e., on the target line) in Experiment 2. Similarly, distant backgrounding did not eliminate the consistency effect in either experiment, suggesting further that location information was being maintained in a highly-accessible state in the mental representation of the subjects, even across several sentences of text that did not refer to location information.

As noted above, our results stand in contrast to those of Smith and O'Brien (2012), and thus so do our conclusions about the representation of location information. Two possible reasons why this is the case are: first, our passages were written with explicit aim of associating goal and location information, whereas Smith and O'Brien's passages manipulated location more cleanly, separate from other situational dimensions; second, in our passages the location cues involved repetition of the words used initially to describe them (e.g., in Table 1, the words his seat on the plane were repeated in the cue-present condition). This second difference is important, but the consistency effect clearly emerged without the cue present on the spillover sentence in Experiment 1 and on the target sentence in Experiment 2; thus, the explicit repetition of the location cue is not the sole driver of the consistency effect. With respect to the first difference, the isolated manipulation of location is a strength of Smith and O'Brien's research 
design, but may limit the generalizability of their findings to the extent that typical narratives do not consistently dissociate these dimensions (see Magliano \& Zacks, 2011, for a discussion of this in the context of film and film editing conventions). Our intuition is that in most narratives, as characters move from place to place, it is usually for some purpose, making the dissociation of movement from goal-directed action artificial. By associating location and goals in our passages, any conclusions we draw about the processing of location alone are limited, given the findings supporting the importance of unfulfilled goals to moment-by-moment comprehension (e.g., Bloom, Fletcher, van den Broek, Reitz, \& Shapiro 1990; Lutz \& Radvansky, 1997).

One other constraint on the conclusions we are able to draw is based on the nature of the location manipulation. In all cases, in the consistent condition, the protagonist in our passages was described as being in a new location consistent with completing the goal. However, in the inconsistent-location condition, the character would either not move or would move to some other location than where the character needed to go to complete the goal. However, to the extent that character movement in the inconsistent-location condition acts as a shift, this would arguably make integration of the later critical sentence easier rather than harder, arguably reducing the magnitude of the inconsistency effect. Nevertheless, only a more-constant treatment of character movement in the inconsistent condition would address this limitation directly.

We believe that trying to examine the representation and processing of location separate from other aspects of a situation model is likely to tell us little more than we already know: Readers can accurately represent and quickly retrieve location information when they are completing a task that demands they do so, either to a high degree (e.g., memorizing a map) Morrow et al., 1987) or to a lesser extent (e.g., following instructions to pay attention to spatial information; Hakala, 1999; Smith \& O’Brien, 2012). When location information is largely 
separated from other situational dimensions, either by careful experimental design or by using more-descriptive-than-narrative materials, readers do not appear to closely track location or keep it in a readily accessible state (de Vega, 1995; Smith \& O'Brien, 2012). It is notable that the only study that we know of that has orthogonally manipulated spatial information alongside other situational dimensions (Sundermeier et al., 2005) showed that spatial information became highly accessible following a causal coherence break, but not prior to the coherence break. Our findings can be viewed as evidence that readers noticed a spatial rather than causal coherence break.

We do not take these results to indicate that readers always track location and keep it in a highly-accessible state in memory. Instead, these results may be framed as an indicator of the flexibility that readers have in tracking situational dimensions, in a manner consistent with a moderate extension of Sanford and Garrod's $(1981,1998)$ scenario mapping and focus (SMF) theory. According to the SMF theory, information from a text, as well as additional information from general knowledge (e.g., inferences, schematic knowledge) is stored in two dynamic memory structures called explicit focus and implicit focus. Explicit focus is where information about currently-relevant discourse entities is stored; implicit focus is where information about scenarios is stored. These two structures are linked by mappings from representations in explicit focus (e.g., of entities like a protagonist) to scenario structures in implicit focus. Sanford and Garrod posited that scenario structures contain role slots; for example, in a scenario in which someone is driving, there are potentially role slots for a driver, for a destination, and so on. Information associated with scenario role slots is represented in a highly-accessible state (Anderson et al., 1983; Levine \& Klin, 2001). For example, Anderson et al. found that reference to scenario-stereotypic entities (e.g., a waiter in a restaurant) in a short written vignette was costfree, as indexed by reading time, so long as the scenario continued. Similarly, Levine and Klin 
found that definite reference to previously-unmentioned scenario-stereotypic entities, such the trees in a story about a forest, incurred no measurable reading-time cost, even if several sentences were interpolated between the last mention of the forest and reference to the trees. Both Anderson et al. and Levine and Klin found that if the scenario shifted, such that there was a time change longer than the typical scenario (e.g., five hours vis-à-vis a restaurant) or a location change, such reference was no longer felicitous. This indicates that scenario role slots stay accessible during a scenario and have reduced accessibility when the scenario ends. This theoretical idea can be extended easily to include the claim that scenario structures may be created for protagonist goals, and these may have role slots for the individual seeking to achieve the goal, locations or objects needed to achieve the goal, and so on. Critically, according to the SMF theory, implicit focus "consists of a currently active part of long-term memory" (1998, p. 163). Thus, given the extension of scenarios to include attempts to complete goals, if the location that a goal is to be achieved is relevant or salient, information about the location may well be in a highly-active state in memory. This proposal about the relative salience of dimensions and their impact on moment-to-moment processing might be incorporated into the proposal by Kurby and Zacks (2012) that some situational changes lead to global updating, such that a reader might abandon one representation and create a new one, whereas others lead to incremental updating, which leaves an ongoing representation more intact even with situation changes.

An alternative, but not mutually exclusive, explanation of these results also does not rely on the notion that location information is special. Instead, it may be the case that situational dimensions such as time, space, and characters (Zwaan et al., 1995) will play a more or less important role in moment-by-moment processing depending on the strength of their connection to currently-important entities. A claim such as this can be accommodated by O'Brien and 
Cook's (2016) resonance, integration, and validation (RI-Val) model, an extension of Myers and O'Brien's (1998) resonance model. According to the RI-Val model, information that is not currently in working memory is reinstated when the contents of working memory signal to longterm memory and the target information resonates, returning to an active state. As soon as a critical mass of information is reinstated, integration of current and reinstated information can begin, and this integrated information can then be validated against information from the narrative and general knowledge. Because the three processes operate in parallel, but integration and validation rely on output from resonance and integration, respectively, anything that delays one of the processes may delay others, and anything that speeds up one of the processes may speed up others. In this manner, the presence of the explicit location cue may make information resonate more quickly, leading to faster integration and validation, consistent with the earlier inconsistency effects we observed. Initial findings in support of the RI-Val model (e.g., Cook \& O'Brien, 2014) focused on validation of information against general knowledge. Our research, especially the results of Experiment 1, extends these findings to validation of information that is explicit in text (cf. Williams, Cook, \& O'Brien, 2018). Much of the evidence supporting the resonance model - and by extension the RI-Val model update to it - has focused on the effect of variables that cause information to be more or less accessible in memory generally. Increasing distance between when information is encoded and the time of retrieval makes reinstatement of information more time-consuming (e.g., O'Brien, 1987). Increased elaboration of information at encoding makes reinstatement of information more likely (e.g., O'Brien, Plewes, \& Albrecht, 1990). Retrieval cues at the time information is needed makes reinstatement of information more likely (e.g., Albrecht \& Myers, 1995). To this list of factors that govern the reinstatement and thus the accessibility of information in memory, we propose adding the strength of the 
connection between current entities and the information that is needed, specifically as a function of relevance or functionality (e.g., Radvansky \& Copeland, 2000; Sundermeier et al., 2005). The idea that well-integrated information, perhaps even large quantities of information, should be easy to retrieve has been proposed in the context of long-term working memory (Ericsson \& Kintsch, 1995). Including such a proposition in a memory-based processing theory like the resonance model would expand its scope with a fairly simple step, providing a new avenue for further exploration of the dynamic processing of information necessary during text comprehension. 


\section{References}

Albrecht, J. E., \& Myers, J. L. (1995). Role of context in accessing distant information during reading. Journal of Experimental Psychology: Learning, Memory, and Cognition, 21, 1459-1468.

Albrecht, J. E., \& O'Brien, E. J. (1993). Updating a mental model: Maintaining both local and global coherence. Journal of Experimental Psychology: Learning, Memory, and Cognition, 19, 1061-1070.

Anderson, A., Garrod, S. C., \& Sanford, A. J. (1983). The accessibility of pronominal antecedents as a function of episode shifts in narrative text. Quarterly Journal of Experimental Psychology, 35A, 427-440.

Barr, D. J., Levy, R., Scheepers, C., \& Tily, H. J. (2013). Random effects structure for confirmatory hypothesis testing: Keep it maximal. Journal of Memory and Language, 68, 255-278.

Bates, D., Maechler, M., Bolker, B., \& Walker, S. (2015). Fitting linear mixed-effects models using lme4. Journal of Statistical Software, 67, 1-48.

Bloom, C. P., Fletcher, C. R., van den Broek, P., Reitz, L., \& Shapiro, B. P. (1990). An on-line assessment of causal reasoning during comprehension. Memory \& Cognition, 18, 65-71.

Chan, G. C., Foy, J. E., \& Magliano, J. P. (2018). Factors that affect crossover between multiple worlds within a narrative. Discourse Processes, 55, 666-685.

Cook, A. E., Guérard, S., Was, C. A., \& O'Brien, E. J. (2007). Foregrounding effects during reading, revisited. Discourse Processes, 26, 109-129.

Cook, A. E., \& O'Brien, E. J. (2014). Knowledge activation, integration, and validation during narrative text comprehension. Discourse Processes, 51, 26-49. 
de Vega, M. (1995). Backward updating of mental models during continuous reading of narratives. Journal of Experimental Psychology: Learning, Memory, and Cognition, 21, 373-385.

Ditman, T., Holcomb, P. J., \& Kuperberg, G. R. (2008). Time travel through language: Temporal shifts rapidly decrease information accessibility during reading. $P B \& R, 15,750-756$.

Ericsson, K. A., \& Kintsch, W. (1995). Long-term working memory. Psychological Review, 102, 211-245.

Gernsbacher, M. A. (1990). Language comprehension as structure building. Hillsdale, NJ: Erlbaum.

Gerrig, R. J., \& McKoon, G. (1998). The readiness is all: The functionality of memory-based text processing. Discourse Processes, 26, 67-86.

Gerrig, R. J., \& O'Brien, E. J. (2005). The scope of memory-based processing. Discourse Processes, 39, 225-242.

Gillund, G., \& Shiffrin, R. M. (1984). A retrieval model for both recognition and recall. Psychological Review, 91, 1-67.

Graesser, A. C., Millis, K. K., \& Zwaan, R. A. (1997). Discourse comprehension. Annual Review of Psychology, 48, 163-189.

Hakala, C. M. (1999). Accessibility of spatial information in a situation model. Discourse Processes, 27(3), 261-279.

Hintzman, D. L. (1986). "Schema abstraction" in a multiple-trace memory model. Psychological Review, 93, 411-428.

Jarvis, B. (2008). DirectRT v2008. New York: Empirisoft.

Kelter, S., Kaup, B., \& Claus, B. (2004). Representing a sequence of events: A dynamic view of 
narrative comprehension. Journal of Experimental Psychology: Learning, Memory, and Cognition, 30, 451-464.

King, S. (1982). The dark tower: The gunslinger. New York, NY: Plume.

Kreuz, R. J., \& Roberts, R. M. (1993). The empirical study of figurative language in literature. Poetics, 22, 151-169.

Kurby, C. A., \& Zacks, J. M. (2012). Starting from scratch and building brick by brick in comprehension. Memory \& Cognition, 40, 812-826.

Kuznetsova, A., Brockhoff, P. B., \& Christensen, R. H. B. (2016). lmerTest: Tests in Linear Mixed Effects Models. R package version 2.0-33. http://CRAN.Rproject.org/package $=$ lmerTest

Levine, W. H., \& Klin, C. M. (2001). Tracking of spatial information in narratives. Memory \& Cognition, 29, 327-335.

Luke, S. G. (2017). Evaluating significance in linear mixed-effects models in R. Behavior Research Methods, 49, 1494-1502.

Lutz, M. F., \& Radvansky, G. A. (1997). The fate of completed goal information in narrative comprehension. Journal of Memory and Language, 36, 293-310.

Magliano, J. P., \& Zacks, J. M. (2011). The impact of continuity editing in narrative film on event segmentation. Cognitive Science, 35, 1489-1517.

McKoon, G., \& Ratcliff, R. (1992). Inference during reading. Psychological Review, 99, 440466.

Mitchell, D. C. (1984). An evaluation of subject-paced reading tasks and other methods for investigating immediate processes in reading. In D. Kieras \& M. A. Just (Eds.), New methods in reading comprehension research (pp. 69-89). Hillsdale, N.J.: Erlbaum 
Morrow, D. G., Greenspan, S. L., \& Bower, G. H. (1987). Accessibility and situation models in narrative comprehension. Journal of Memory and Language, 26, 165-187.

Myers, J. L., \& O'Brien, E. J. (1998). Accessing the discourse representation during reading. Discourse Processes, 26, 131-157.

O'Brien, E. J. (1987). Antecedent search processes and the structure of text. Journal of Experimental Psychology: Learning, Memory, and Cognition, 13, 278-290.

O'Brien, E. J., \& Albrecht, J. E. (1992). Comprehension strategies in the development of a mental model. Journal of Experimental Psychology: Learning, Memory, and Cognition, $18,777-784$.

O’Brien, E. J., \& Cook, A. E. (2016). Coherence threshold and the continuity of processing: The RI-Val model of comprehension. Discourse Processes, 53, 326-338.

O'Brien, E. J., \& Myers, J. L. (1999). Text comprehension: A view from the bottom up. In S. R. Goldman, A. C. Graesser, \& T. Trabasso (eds.) Narrative comprehension, causality, and coherence: Essays in honor of Tom Trabasso (pp. 35-53). Mahwah, NJ: Erlbaum.

O'Brien, E. J., Plewes, P. S., \& Albrecht, J. E. (1990). Antecedent retrieval processes. Journal of Experimental Psychology: Learning, Memory, and Cognition, 16, 241-249.

R Core Team (2017). R: A language and environment for statistical computing. R Foundation for Statistical Computing, Vienna, Austria. https://www.R-project.org/.

Radvansky, G. A., \& Copeland, D. E. (2000). Functionality and spatial relations in memory and language. Memory \& Cognition, 28, 987-992.

Rapp, D. N., \& Taylor, H. A. (2004). Interactive dimensions in the construction of mental representations of text. Journal of Experimental Psychology: Learning, Memory, and Cognition, 30, 988-1001. 
Radvansky, G. A., \& Copeland, D. E. (2010). Reading times and the detection of event shift processing. Journal of Experimental Psychology: Learning, Memory, and Cognition, 36, 210-216.

Ratcliff, R. (1978). A theory of memory retrieval. Psychological Review, 85, 59-108.

Rinck, M., \& Weber, U. (2003). Who when where: An experimental test of the event-indexing model. Memory \& Cognition, 31, 1284-1292.

Sanford, A. J., \& Garrod, S. C. (1981). Understanding written language: Explorations in comprehension beyond the sentence. Chichester, England: John Wiley \& Sons.

Sanford, A. J., \& Garrod, S. C. (1998). The role of scenario mapping in text comprehension. Discourse Processes, 26, 159-190.

Schank, R. C., \& Abelson, R. P. (1977). Scripts, plans, goals and understanding: An inquiry into human knowledge structures. Hillsdale, NJ: Erlbaum.

Scott Rich, S, \& Taylor, H. A. (2000). Not all narrative shifts function equally. Memory \& Cognition, 28, 257-1266.

Smith, E. R., \& O’Brien, E. J. (2012). Tracking spatial information during reading: a cue-based process. Memory \& Cognition, 40, 791-801.

Sparks, J. E., \& Rapp, D. N. (2011). Readers' reliance on source credibility in the service of comprehension. Journal of Experimental Psychology: Learning, Memory, and Cognition, $37,230-247$.

Speer, N. K., Reynolds, J. R., \& Zacks, J. M. (2007). Human brain activity time-locked to narrative event boundaries. Psychological Science, 18, 449-455.

Suh, S. Y., \& Trabasso, T. (1993). Inferences during reading: Converging evidence from discourse analysis, talk-aloud protocols, and recognition priming. Journal of Memory and 
Language, 32, 279-300.

Sundermeier, B. A., van der Broek, P., \& Zwaan, R. A. (2005). Causal coherence and the availability of locations and objects during narrative comprehension. Memory \& Cognition, 33, 462-470.

Therriault, D. J., \& Raney, G. E. (2007). Processing and representing temporal information in narrative text. Discourse Processes, 43, 173-200.

Thompson, A. N., \& Radvansky, G. A. (2016). Event boundaries and anaphoric reference. Psychonomic Bulletin \& Review, 23, 849-856.

van Dijk, T. A., \& Kintsch, W. (1983). Strategies of discourse comprehension. New York: Academic Press.

Weingartner, K. M., \& Myers, J. L. (2013). Effects of changes in narrative time on eye movements and recognition responses. Journal of Cognitive Psychology, 3, 283-298.

Williams, C. R., Cook, A. E., \& O'Brien, E. J. (in press). Validating semantic illusions: Competition between context and general world knowledge. Journal of Experimental Psychology: Learning, Memory, and Cognition.

Zacks, J., Speer, N., \& Reynolds, J.R. (2009). Segmentation in reading and film comprehension. Journal of Experimental Psychology: General, 138, 307-327.

Zwaan, R. A. (1996). Processing narrative time shifts. Journal of Experimental Psychology: Learning, Memory, and Cognition, 22, 1196-1207.

Zwaan, R. A., Langston, M. C., \& Graesser, A. C. (1995). The construction of situation models in narrative comprehension: An event-indexing model. Psychological Science, 6, 292297.

Zwaan, R. A., Magliano, J. P., \& Graesser, A. C. (1995). Dimensions of situation model 
construction in narrative comprehension. Journal of Experimental Psychology: Learning, Memory, and Cognition, 21, 386-397.

Zwaan, R. A., \& Radvansky, G. A. (1998). Situation models in language comprehension and memory. Psychological Bulletin, 123, 162-185.

Zwaan, R. A., Radvansky, G. A., Hilliard, \& Curiel, J. M. (1998). Constructing multidimensional situation models during reading. Scientific Studies of Reading, 2, 199-220. 
Table 1

Sample passage

Introduction: A hurricane was rolling in from the Gulf Coast, and Tom needed to evacuate.

Traffic was so bad that he arrived at the airport late for his flight, and now he had only thirty minutes to make it from the parking lot to his seat on the plane. The airport was absolutely packed.

\section{$\underline{\text { Goal/location manipulation }}$}

(consistent) Tom managed to get through security with enough time to take his seat on his plane.

(inconsistent) The lines to get past security were so long that Tom was stuck waiting in line.

Backgrounding manipulation (additional distant backgrounding in brackets): The wind was increasing and the sky was already black. [The incoming storm was supposed to be the worst of the season. Tom never thought much about climate change, but everyone on the news and on Facebook was talking about it constantly. The hurricane was stronger than initially forecast, and there had been little time to prepare. Tom's phone had been ringing nonstop with calls from worried relatives watching the news.]

Critical sentences (explicit cue in brackets): Tom [sat in his seat on the plane and] heard the announcement for everyone to fasten their seatbelts. Tom could hear someone near him praying out loud.

Conclusion: Everyone around Tom was nervous at the sound of rain beginning to fall outside. 


\section{Table 2}

Model-estimated condition means in ms (with 95\% confidence intervals) for target and spillover lines, controlling for line length in letters, for Experiment 1.

\begin{tabular}{|c|c|c|c|c|c|}
\hline \multirow[b]{3}{*}{ line } & \multirow[b]{3}{*}{ location } & \multicolumn{4}{|c|}{ backgrounding } \\
\hline & & \multicolumn{2}{|c|}{ close } & \multicolumn{2}{|c|}{$\underline{\text { distant }}$} \\
\hline & & cue & no cue & cue & no cue \\
\hline \multirow[t]{4}{*}{ target } & consistent & $2145[1974$, & $2429[2272$ & $2173[2019$, & $2407[2251$, \\
\hline & & 2317] & 2586] & 2326] & 2562] \\
\hline & inconsistent & 2362 [2191, & 2497 [2341, & $2308[2155$, & 2459 [2304, \\
\hline & & 2532] & 2652] & 2462] & 2615] \\
\hline \multirow[t]{4}{*}{ spillover } & consistent & $2074[1933$, & $2154[2009$ & $2052[1910$ & 2094 [1949, \\
\hline & & 2216] & 2299] & 2193] & 2239] \\
\hline & inconsistent & 2173 [2031, & $2301[2156$, & 2046 [1904, & 2239 [2094, \\
\hline & & 2315] & 2446] & 2188] & 2384] \\
\hline
\end{tabular}




\begin{tabular}{|c|c|c|c|c|c|}
\hline \multicolumn{6}{|l|}{ Table 3} \\
\hline \multicolumn{6}{|c|}{ Model-estimated condition means in ms (with $95 \%$ confidence intervals) for target and } \\
\hline \multicolumn{6}{|c|}{ spillover lines, controlling for line length in letters, for Experiment 2.} \\
\hline \multirow[b]{3}{*}{ line } & \multirow[b]{3}{*}{ location } & \multicolumn{4}{|c|}{$\underline{\text { backgrounding }}$} \\
\hline & & \multicolumn{2}{|c|}{$\underline{\text { close }}$} & \multicolumn{2}{|c|}{$\underline{\text { distant }}$} \\
\hline & & cue & no cue & cue & no cue \\
\hline \multirow[t]{4}{*}{ target } & consistent & $2171[2015$, & $2228[2071$ & $2180[2025$ & 2067 [1911, \\
\hline & & 2326] & 2384] & 2336] & 2223] \\
\hline & inconsistent & $2452[2299$ & $2398[2243$ & $2355[2200$ & 2273 [2116, \\
\hline & & 2605] & 2554] & 2510] & 2430] \\
\hline \multirow[t]{4}{*}{ spillover } & consistent & $2020[1872$, & $2015[1868$, & $2015[1867$, & $1897[1750$, \\
\hline & & 2167] & 2163] & 2163] & 2045] \\
\hline & inconsistent & $2178[2030$ & $2101[1953$ & 2054 [1907, & $2003[1855$, \\
\hline & & 2326] & 2249] & 2202] & 2151] \\
\hline
\end{tabular}




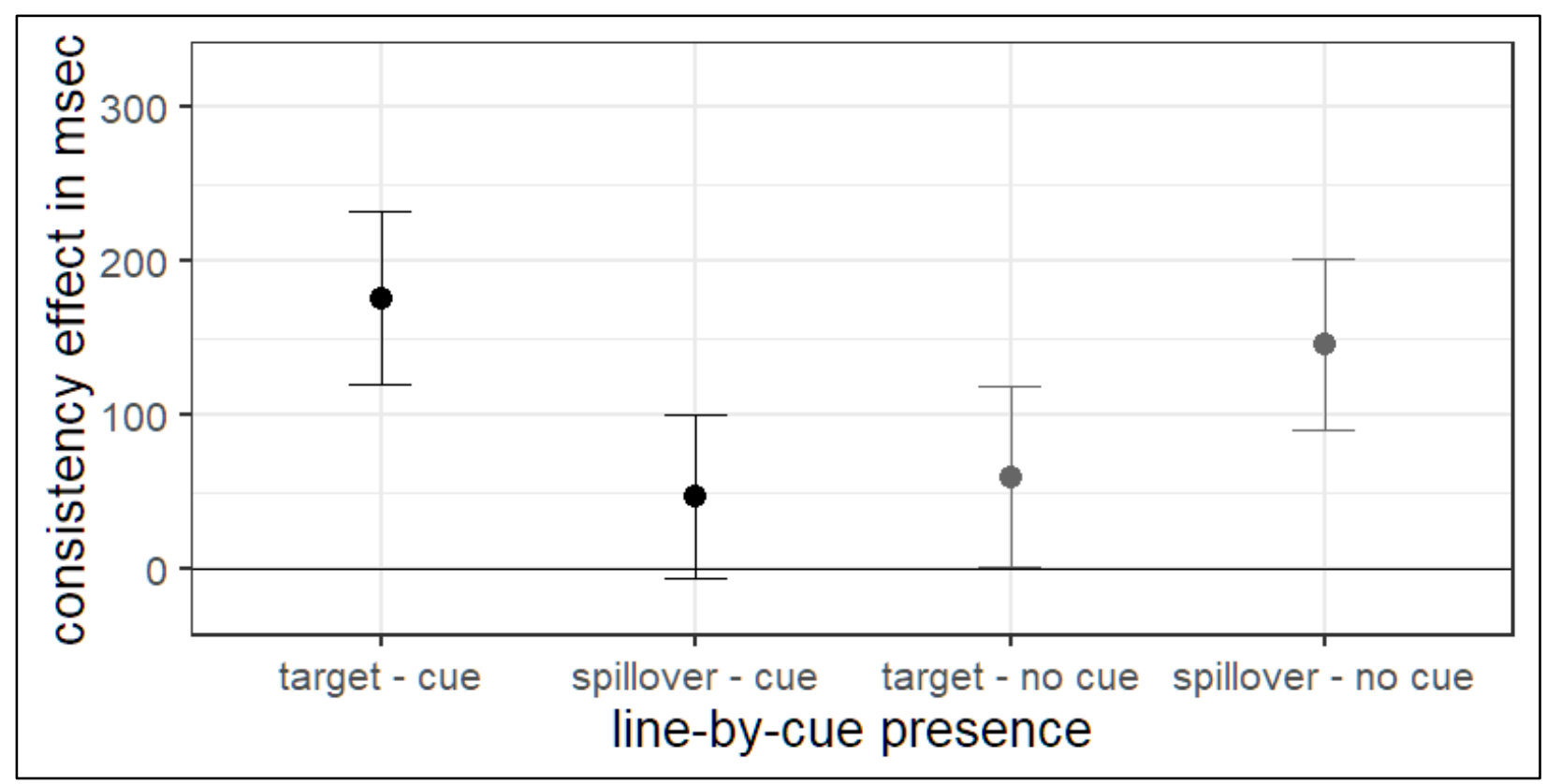

Figure 1. Experiment 1 model-estimated consistency effects (inconsistent-condition minus consistent-condition reading times) in milliseconds for target and spillover sentences as a function of cue presence, controlling for sentence length. Error bars represent the 95\% confidence interval for each difference score.

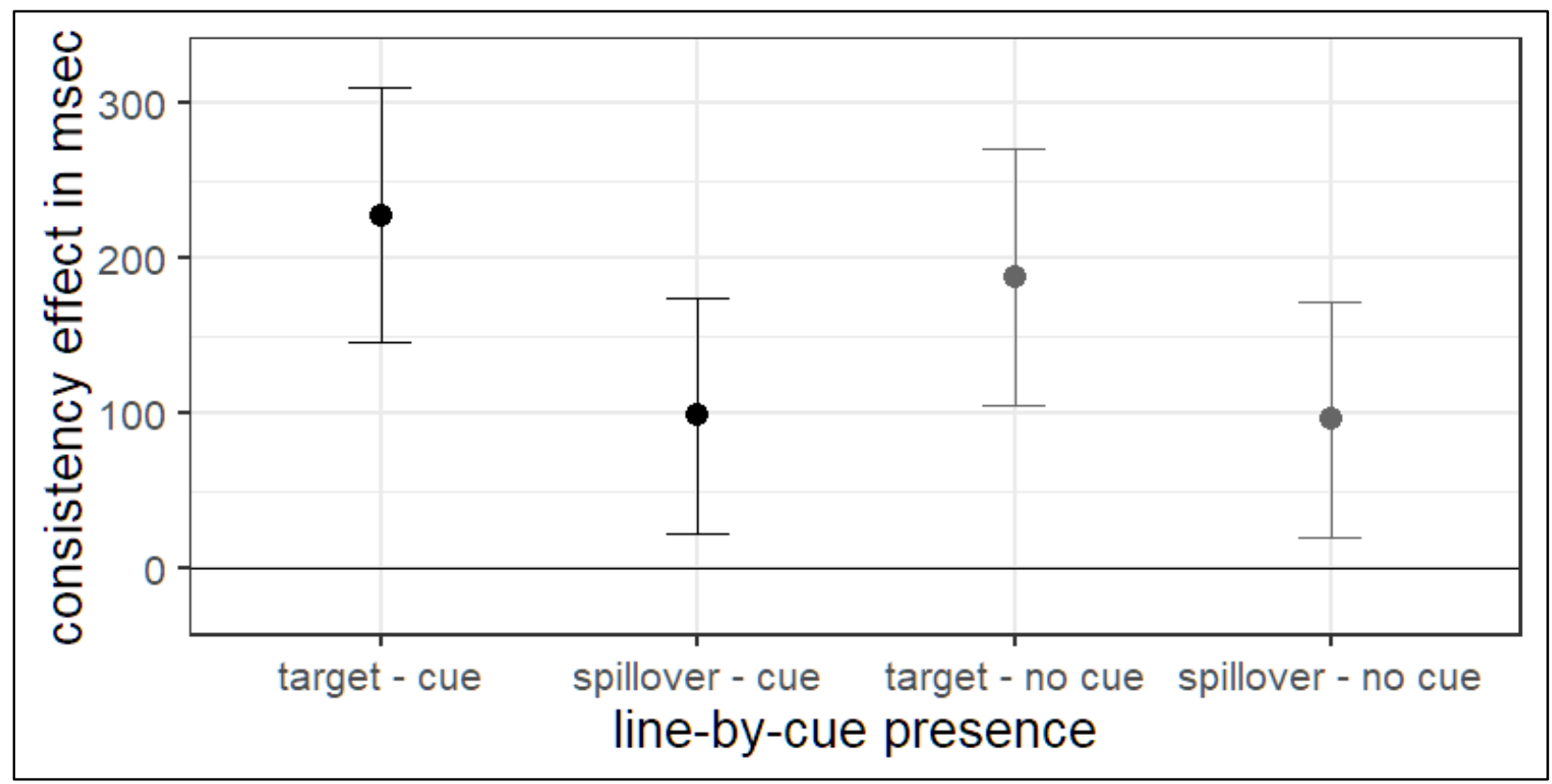

Figure 2. Experiment 2 model-estimated consistency effects (inconsistent-condition minus consistent-condition reading times) in milliseconds for target and spillover sentences as a function of cue presence, controlling for sentence length. Error bars represent the 95\% confidence interval for each difference score. 


\section{Appendix}

In this appendix, we report re-analysis of the findings presented in the Results section of Experiment 1, using conventional analyses in which subjects and items, in separate analyses, are treated as random-effects variables. Subscripts of 1 indicate that subjects were treated as a random-effects variable, whereas subscripts of 2 indicate that items were treated as a randomeffects variable. For both the target and spillover sentences, 2 (location: consistent, inconsistent) $\times 2$ (backgrounding: close, distant) $\times 2$ (cue: cue present, no cue) analyses of variance were conducted on mean scores for subjects and for items. For the by-subjects analysis, the first two factors were repeated-measures and the latter was manipulated between-subjects; all three factors were repeated-measures for items. Unlike the analyses using linear mixed models reported in the Results section of Experiment 1, the analyses reported in this Appendix do not control for line length. Effect-sizes and condition means are based on the by-subjects analysis.

\section{Target line}

There was a significant consistency effect on the target line. Reading times were significantly longer when they were inconsistent with the protagonist's location $(M=2394, S E=$ $38)$ than when they were consistent $(M=2325, S E=39), F_{1}(1,183)=27.84, p<.001, \eta_{\mathrm{p}}^{2}=.13$, $F_{2}(1,23)=27.31, p<.001$. There was also a significant effect of cue on the target line. Reading times were significantly longer when a cue was present $(M=2514, S E=50)$ than when it was $\operatorname{not}(M=2157, S E=52), F_{1}(1,183)=24.14, p<.001, \eta_{\mathrm{p}}^{2}=.12, F_{2}(1,23)=100.76, p<.001$; this effect is almost certainly due to the longer sentences in the cue-present condition. The main effect of backgrounding was not significant, nor were the backgrounding-by-cue, location-bybackgrounding, nor the three-way interaction (all $F \mathrm{~s}<1.6$ ).

The interaction between location and cue was significant by subjects but not by items, 
$F_{1}(1,183)=5.41, p=.021, \eta_{\mathrm{p}}^{2}=.03, F_{2}(1,23)=2.16, p=.155$. Two planned simple-effect tests of the consistency effect, one with and one without a location-cue present, were executed using a Bonferroni-adjusted alpha level of .025 for each. When there was no cue present, reading times were non-significantly longer in the inconsistent condition $(M=2190, S E=54)$ than in the consistent condition $(M=2125, S E=52), F_{1}(1,88)=3.86, p=.053, F_{2}(1,23)=3.20, p=.087$. When there was a cue present, reading times were significantly longer in the inconsistent condition $(M=2599, S E=54)$ than in the consistent condition $(M=2430, S E=54), F_{1}(1,95)=$ $32.67, p<.001, \eta_{\mathrm{p}}^{2}=.26, F_{2}(1,23)=14.98, p=.001$.

\section{Spillover line}

There was a significant consistency effect on the spillover line. Reading times were significantly longer when they were inconsistent with the protagonist's location $(M=2198, S E=$ 40) than when they were consistent $(M=2084, S E=38), F_{1}(1,183)=21.97, p<.001, \eta_{\mathrm{p}}^{2}=.11$, $F_{2}(1,23)=11.48, p=.003$. The effect of cue on the target line was significant by items but not by subjects, $F_{1}(1,183)=1.74, p=.189, F_{2}(1,23)=15.74, p=.001$, with longer readings times when there was no cue $(M=2183, S E=88)$ than when the cue was present $(M=2092, S E=86)$. The main effect of backgrounding was significant, such that reading times were significantly longer with close backgrounding $(M=2183, S E=39)$ than with distant backgrounding $(M=$ 2099, $S E=39), F_{1}(1,183)=11.84, p=.001, \eta_{\mathrm{p}}^{2}=.06, F_{2}(1,23)=7.21, p=.013$. Neither the backgrounding-by-cue, location-by-backgrounding, nor the three-way interaction was significant (all $F \mathrm{~s}<3.1)$.

The interaction between location and cue was not significant, $F_{1}(1,183)=2.74, p=.021$, $F_{2}(1,23)=2.28, p=.145$. Because of theoretical importance, two planned simple-effect tests of the consistency effect, one with and one without a location-cue present, were executed using a 
Bonferroni-adjusted alpha level of .025 for each. When there was no cue present, reading times were significantly longer in the inconsistent condition $(M=2267, S E=62)$ than in the consistent condition $(M=2112, S E=55), F_{1}(1,88)=17.95, p<.001, \eta_{\mathrm{p}}^{2}=.17, F_{2}(1,23)=15.11, p=.001$. When there was a cue present, reading times were not significantly longer in the inconsistent condition $(M=2129, S E=50)$ than in the consistent condition $(M=2056, S E=52), F_{1}(1,95)=$ $5.156, p=.0254, \eta_{\mathrm{p}}^{2}=.05, F_{2}(1,23)=2.70, p=.114$.

\section{Summary}

The results of the conventional analyses broadly match the pattern of findings that the linear mixed model analyses revealed in Experiment 1. First, there was a consistency effect on both the target and spillover sentences. Second, the consistency effect was more prominent on the target line than the spillover line when a cue was present but was more prominent on the spillover line than the target line when no cue was present (see Figure 1). 